\title{
Overexpression of EGR-1 modulates the activity of NF-кB and AP-1 in prostate carcinoma PC-3 and LNCaP cell lines
}

\author{
EDUARDO PARRA $^{1}$, JORGE FERREIRA $^{2}$ and ARNALDO ORTEGA ${ }^{1}$ \\ ${ }^{1}$ Biomedical Experimental Laboratory, Sciences Faculty, University of Tarapaca, Arica, Avenida General \\ Velásquez 1775, Campus Velásquez, Arica; ${ }^{2}$ Programme of Molecular and Clinical Pharmacology, ICBM \\ Medical Faculty, University of Chile, Avenida Independencia 1027, Independencia, Santiago, Chile
}

Received February 2, 2011; Accepted March 15, 2011

DOI: 10.3892/ijo.2011.1047

\begin{abstract}
To address elements that might uniquely characterize EGR-1 mediated signaling, the expression of two transcription factors, namely, nuclear factor kappa $\mathrm{B}(\mathrm{NF}-\mathrm{\kappa B})$ and activator protein-1 (AP-1) were studied. PC-3 and LNCaP prostate carcinoma cell lines were transiently transfected with wildtype Egr-1 expression plasmid (pCMV-Egr-1) and treated with cisplatin and TPA. Overexpression of EGR-1 was found to induce nuclear expression of both, NF- $\mathrm{kB}$ and AP1. However, the intensity of the induced AP-1 and NF- $\mathrm{kB}$ was diminished after cisplatin treatment, but not after TPA. Our findings confirm that the overexpression of wild-type Egr-1 caused a marked increase in cell proliferation in PC-3 and LNCaP proliferation in a 14-day soft agar colony forming assay. In addition, luciferase reporter gene assay showed that the transcriptional activity of AP-1 and NF- $\mathrm{KB}$ in PC-3 and LNCaP prostate carcinoma cell lines was also modulated by the overexpression of EGR-1 in these cells using tandem repeated

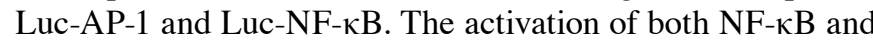
AP-1 are key steps in the cascade of events following the activation of the EGR-1 gene. It was revealed that overexpression of EGR-1 selectively increased AP-1 and NF- $\mathrm{kB}$ activation, and that the activation of these nuclear factors appears to be essential for the induction of proliferation and anchorage independence in activated PC-3 and LNCaP cells. However, the mechanism underlying the modulation of AP-1 and NF- $\mathrm{KB}$ by the overexpression of EGR-1 is still unknown.
\end{abstract}

\section{Introduction}

The early growth response protein (Egr-1) is a $\mathrm{C}_{2} \mathrm{H}_{2}$-zinc finger-containing transcriptional regulator involved in the control of cell proliferation and apoptosis. The induction of

Correspondence to: Professor Eduardo Parra Villegas, Biomedical Experimental Laboratory, Sciences Faculty, Campus Velasquez, University of Tarapaca, Avenida General Velásquez 1775, Arica, Chile E-mail: eparra@uta.cl

Key words: prostate carcinoma, early growth response gene, nuclear factors, AP-1, NF- $\kappa \mathrm{B}$, soft agar assay
Egr-1 by external stimuli is generally transient but appears to be sustained in some prostate tumor cell lines and tumors, suggesting that Egr-1 stimulates tumor cell growth and that could have an important function because its expression level increases with the degree of malignancy as measured by the Gleason grade of the tumor (1). This seems to be specific to prostate tumor cells, because in mammary and lung tumors, as well as most normal tissues, Egr-1 expression is low (2-6). In addition Egr-1 overexpression is correlated with the loss of its co-repressor NAB2 in primary prostate carcinoma (6-8). This disruption of the balance between Egr-1 and NAB2 expression results in a high Egr-1 transcriptional activity in prostate carcinoma cells (1). In contradiction, in breast, lung and brain tumors, Egr-1 expression is often absent or reduced and when re-expressed, results in growth suppression (2,4-10). Another contradiction is that after stress stimuli to some cell types, Egr-1 is required for programmed cell death or apoptosis in both normal and tumor cells (11-13). Egr-1 also plays a role in tumor progression, through the hypoxic signal generated in growing tumors. Egr-1 is highly induced under these conditions and its activities stimulate angiogenesis $(6,10,14,15)$. However, one of the major concerns about Egr-1 overexpression in carcinomas is that it would become associated with a loss in functionality of the prostate cells and/or the development of autonomous growth. In this study, by evaluating the effects of the overexpression of EGR-1 treated with different stimuli, we found a similar timing of activation being suggestive for a common and co-linear regulation for the two nuclear factors (AP-1 and NF- $\kappa$ B). Nuclear factor- $\kappa \mathrm{B}(\mathrm{NF}-\kappa \mathrm{B})$ and activator protein 1 (AP-1) are well-characterized ubiquitously expressed transcription factors that play important roles in the response to cellular stress situations. In unstimulated resting cells, NF- $\mathrm{KB}$ and AP-1 are inactive $(16,18)$. A prominent portion of the classical NF- $\kappa B$ target gene program includes chemokines and cytokines, which promote inflammation and angiogenesis $(18,19,24)$. In addition to the role of $\mathrm{NF}-\kappa \mathrm{B}$ in directly promoting cancer cell survival, these factors provide selective advantages for tumor growth in the microenvironment via stimulation of inflammatory cell infiltration and angiogenesis (24-26). These transcription factors are induced by a great variety of stimuli and conditions that represent internal or external stress situations for the cells. These include pathological stimuli, such as viruses, bacteria, oxidative stress, hypoxia, and 
inflammatory mediators as well as internal cellular stress (e.g., endoplasmic reticulum overload) $(23,24)$. Cisplatin has been widely used as a chemotherapeutic agent to treat several kinds of cancers, although its use is somewhat limited because of cisplatin-resistance $(25,26)$. Cisplatin caused a late and prolonged induction of both ERK1/2 and JNK1 activity in a dose-dependent manner, whereas no significant difference was observed in p38 activity in SKOV-3 cells (27). On the other hands, 12-O-tetradecanoyl-phorbol-13-acetate (TPA), also commonly known as phorbol 12-myristate 13-acetate (PMA), is diester of phorbol and a potent tumor promoter often employed in biomedical research to activate the signal transduction enzyme protein kinase C (PKC) (28-30). Indeed, we show that cisplatin but not TPA increases the activity of $\mathrm{NF}-\mathrm{KB}$ in prostate cells overexpressing Egr-1. In contrast, cisplatin and TPA increases substantially the activity of AP-1, compared with the activity in unstimulated cells. By using a luciferase reporter gene driving by a tandem repeated of AP-1 or NF- $\kappa \mathrm{B}$, we demonstrated the transcriptional effect of the overexpression of EGR-1 in both AP-1 and NF- $\kappa$ B. The effects of the overexpression of Egr-1 and cisplatin or TPA on colony formation ability of the prostate carcinoma cell lines $\mathrm{PC}-3$ or $\mathrm{LNCaP}$ were assessed by soft agar colony formation assay.

Our findings also suggest that AP-1 and NF- $\mathrm{\kappa B}$ levels are necessary for Egr-1 activity and have a sustained effect on Egr-1 signaling in prostate cancer cell lines. Our observations support the concept that growth of prostate cancer cells occurs at a balanced level of Egr-1 and AP-1/NF- $\mathrm{KB}$ expression. Disruption of this balance may play a crucial role in the development of drug resistance observed in prostate cancer cells.

\section{Materials and methods}

Cell lines and culture. Human prostate carcinoma cell lines PC-3 and LNCaP were a gift of Dr Dan Mercola (The SKCC, La Jolla, CA, USA). The cells were cultured in RPMI- 1640 medium supplemented with $100 \mathrm{ml} / \mathrm{l}$ fetal bovine serum (FBS), $8 \times 10^{5} \mathrm{U} / 1$ penicillin and $0.1 \mathrm{~g} / 1$ streptomycin in humidified incubator containing $50 \mathrm{ml} / 1 \mathrm{CO}_{2}$ at $37^{\circ} \mathrm{C}(30-32)$. Tris Borate-EDTA and acrylamide-bisacrylamide (29:1) were obtained from Bio-Rad (Richmond, CA) luciferase assay reagent, lysis buffer and the pGL-2 luciferase vector were obtained from Promega (Madison, WI). Egr-1 antibody was purchased from Santa Cruz Biotechnology (Santa Cruz,CA, USA).Lipofectamine (Life Technologies, Inc., USA). 12-O-tetradecanoylphorbol13 -acetate TPA $(50 \mathrm{nM})$ and cisplatin $(30 \mu \mathrm{M})$ were purchased from Sigma Chemical, Co., St. Louis, USA.

Reverse transcription polymerase chain reaction. $\mathrm{PC}-3$ and LNCaP cells $\left(5 \times 10^{5}\right)$ were seeded onto 6 -well plates. Total RNA was extracted $48 \mathrm{~h}$ after transfection using TRIzol reagent. Reverse transcription was performed using one step RT-PCR kit. The primers of Egr-1 were 5'-AACAGTGGCAACACCTTGTG-3' (forward primer) and 5'-ACTGGTAGCT GGTATTGAGG-3' (reverse primer). The primers of human $\beta$-actin were 5'-TCACCAACTGGGA-CGACAT-3' (forward primer) 5'-GAAGTCCAGGGCGACGTAG-3' (reverse primer). Thermal cycle conditions were as follows: $42^{\circ} \mathrm{C}$ for $30 \mathrm{~min}$, $94^{\circ} \mathrm{C}$ for $2 \mathrm{~min}$, followed by 28 cycles of $94^{\circ} \mathrm{C} 15 \mathrm{sec}, 55^{\circ} \mathrm{C}$
$30 \mathrm{sec}, 72^{\circ} \mathrm{C} 1 \mathrm{~min}$, with a final extension at $72^{\circ} \mathrm{C}$ for $10 \mathrm{~min}$. RT-PCR products were visualized by ethidium bromide-stained agarose gels $(30,32)$.

Western immunoblot analysis. PC-3 and LNCaP transfected with an empty vector (pCMV) or with an expression plasmid for Egr-1 (pCMV-Egr-1) prostate carcinoma cells lines $\left(5 \times 10^{5}\right)$ were seeded onto 6-well plates. Forty-eight hours after transfection, cells were collected and washed twice by cold PBS, and each well was treated with $50 \mathrm{ml}$ lysis buffer $(2 \mathrm{mmol} / \mathrm{l}$ Tris-HCl pH 7.4, $50 \mathrm{mmol} / 1 \mathrm{NaCl}, 25 \mathrm{mmol} / \mathrm{l}$ EDTA, $50 \mathrm{mmol} / \mathrm{l}$ $\mathrm{NaF}, 1.5 \mathrm{mmol} / 1 \mathrm{Na}_{3} \mathrm{VO}_{4}, 1 \%$ Triton X-100, 0.1\% SDS, supplemented with protease inhibitors $1 \mathrm{mmol} / 1$ phenylmethylsulfonylfluoride, $10 \mathrm{mg} / \mathrm{l}$ pepstatin, $10 \mathrm{mg} / \mathrm{l}$ aprotinin, and $5 \mathrm{mg} / \mathrm{l}$ leupeptin) (all from Sigma). Protein concentrations were determined using the Bradford protein assay. Equal amounts of protein $(50 \mu \mathrm{g})$ were separated on a $15 \%$ SDS polyacrylamide gel and transferred to a nitrocellulose membrane (Hybond C, Amersham, Freiburg, Germany). Membranes were blocked in $5 \%$ non-fat dry milk in TBS for $1 \mathrm{~h}$ at room temperature and probed with rabbit anti-Egr-1 antibodies (dilution, 1:500 Santa Cruz Biotechnology, USA) overnight at $4^{\circ} \mathrm{C}$. After 3 times washing with TBS containing $0.1 \%$ Tween 20 , membranes were incubated with anti-rabbit IgG-horseradish-peroxidase (1:5000, Santa Cruz Biotechnology, USA), and developed by luminol mediated chemiluminescence (Appylgen Technologies Inc., China). To confirm equal protein loading, membranes were reprobed with a 1:1000 dilution of an anti-actin antibody (Santa Cruz Biotechnology). Densitometric analyses were performed using Scion Image software (33).

Soft agar colony formation assay. The effect of EGR-1 overexpression alone or in combination with cisplatin or TPA on colony formation ability of the LNCaP and PC-3 cells was assessed by soft agar colony formation assay. Prostate carcinoma cell lines were transfected with an empty vector (pCMV) or with an expression plasmid for Egr-1 (pCMV-Egr-1). The assay was done in six-well plates; in each well, $2 \mathrm{ml}$ of $0.5 \%$ agar (in culture medium) was layered in the bottom followed by $1 \mathrm{ml}$ of $0.38 \%$ agar as the top layer. Approximately 2,000 cells were then plated over the top layer. The cells were treated with cisplatin or TPA and maintained at $37^{\circ} \mathrm{C}$ in a humidified $5 \%$ $\mathrm{CO}_{2}$ atmosphere. At 14 days post treatment, plates were assessed for size and number of colonies (original magnification, $\mathrm{x} 4$ ). Colonies (in a representative field) are indicated $(30,31)$.

Luciferase assay. The AP-1 and NF- $\mathrm{KB}$ reporter plasmid driven by the rat prolactin minimal promoter $(-36$ to +37$)$ under the control of four copies of the human AP-1 site (49) was kindly provided by M. Rincon and R.A- Flavell (section of immunobiology, Howard Hughes Medical Institute, Yale University School of Medicine, New Haven, CT). 5'-TCGATT GAGTCAGGGTAA-3' and the two copies of the NF- $\kappa$ B binding site of the human Ig $\kappa$ light chain enhancer 5'-GGGA CTTTCC-3' (33-35).

To assay for luciferase activity, transfected cells in duplicate wells were cultured for $24 \mathrm{~h}$ before being stimulated with or without cisplatin and TPA for a defined length of time. Cells were harvested, washed twice in PBS and treated with lysis buffer (Luciferase Assay Promega, Madison, WI) for 5-10 min 
on ice. Lysates were spun down for $1 \mathrm{~min}$, and the total supernatants were analyzed using Luciferase Reagent (Promega) and measured in a luminometer (MicroLumat LB 96 P, Berthold) for $5 \mathrm{sec}$. Background measurement was subtracted from each duplicate, and experimental values are expressed either as recorded light units, luciferase activity or as relative activity compared to extracts from unstimulated cells $(34,35)$.

Immunofluorescence. An aliquot of PC-3 and LNCaP cells $(150 \mu \mathrm{l})$, previously transfected with pCMV or pCMV-Egr-1, was cytocentrifuged onto glass slides at $150 \mathrm{~g}$ for $2 \mathrm{~min}$ using a Shandon Cytospin 2 (Thermo Fisher Scientific, Waltham, MA). Cells were fixed with $4 \%$ paraformaldehyde in PBS for $30 \mathrm{~min}$ at room temperature and gently washed in PBS. Cells were then placed in $50 \mathrm{mM} \mathrm{NH} 4 \mathrm{Cl}$ for $5 \mathrm{~min}$ before permeabilization in $0.1 \%$ Triton $\mathrm{X}-100$ in PBS for $3 \mathrm{~min}$ at room temperature. After washing in PBS, the cells were blocked in 2\% BSA for $30 \mathrm{~min}$, washed in PBS, and incubated with antiEGR-1 antibody (1:250 dilution) in a humidity chamber for $1 \mathrm{~h}$ at room temperature. After washing in PBS, the cells were incubated with anti-rabbit IgG conjugated with Alexa Fluor 488 antibodies (1:200 dilution), respectively (Invitrogen, Carlsbad, $\mathrm{CA}$ ) for $1 \mathrm{~h}$ at room temperature in the dark. Nuclei were stained with DAPI $(1 \mu \mathrm{g} / \mathrm{ml})$ for $20 \mathrm{sec}$. Coverslips were fixed to the slides using DakoCytomation fluorescent mounting medium (Dako North America, Inc., Carpinteria, CA). Stained cells were visualized using a Fluorescent microscope (Olympus BX-60, NY), and images were captured using the Spot and Spot 3.2.4 system software (Diagnostic instruments) (36).

Cell culture and assessment of cell growth and viability. The human prostate cancer cell lines LNCaP and PC-3. These cells were grown in DMEM supplemented with 0.5 and/or $10 \%$ heat inactivated FBS, 2 mM glutamine, $1 \%$ penicillinstreptomycin-neomycin in a humidified incubator $\left(5 \% \mathrm{CO}_{2}\right.$ in air at $37^{\circ} \mathrm{C}$ ). Cells were seeded in 6 -well plates prior to cisplatin and/or TPA addition. The cells were incubated with cisplatin $(30 \mu \mathrm{M})$ and /or TPA $(20 \mathrm{nM})$ for $24 \mathrm{~h}$. Cultures were harvested and monitored for cell number by counting cell suspensions with a hemocytometer. Cell growth $\left(2.0 \times 10^{5}\right.$ cells/ well) and viability $\left(1.0 \times 10^{6}\right.$ cells/well) were checked before and after treatment with cisplatin and /or TPA using trypan blue exclusion and examined using phase contrast microscopy.

\section{Results}

It has been shown that EGR-1 is endogenously expressed in LNCaP and PC-3 prostate carcinoma cell lines and that its levels of expression decreased in cells treated with siRNA against EGR-1 (30,32). We have reported that EGR-1 mRNA also is decreased in prostate cancer cell lines treated with a siRNA-Egr-1 (32). Consistent therefore, EGR-1 overexpression will increase LNCaP and PC-3 cell proliferation and independent anchorage.

EGR-1 activity in prostate carcinoma cell lines treated with various stimuli (Fig. 1). EGR-1 is among the early response nuclear factors that plays an important role in the regulation of several genes. To determine the effect of the overexpression
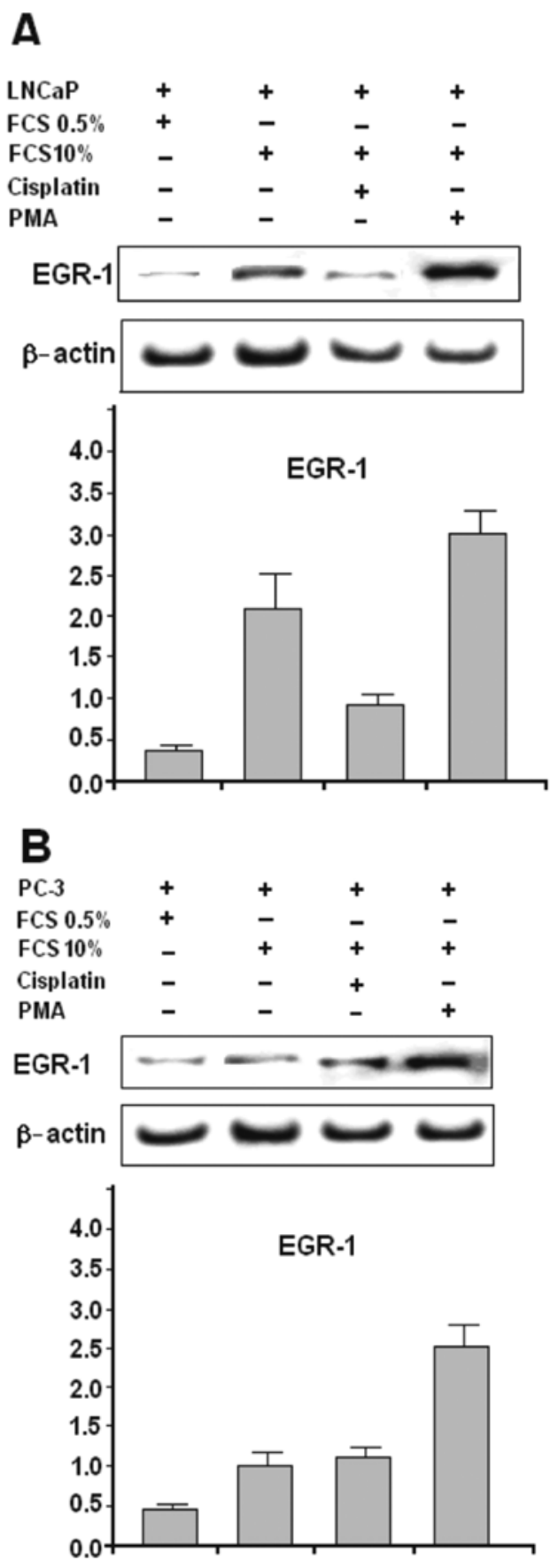

Figure 1. Analysis of Egr-1 expression in $\mathrm{LNCaP}$ (A) and PC-3 (B) prostate carcinoma cells treated with various agents. (A), $\mathrm{LNCaP}$ and (B), PC-3 cells were treated with, FCS $0.5 \%$, FCS $10 \%$ for $24 \mathrm{~h}$, following by cisplatin $(30 \mu \mathrm{M})$ or PMA $(50 \mathrm{nM})$ induction for another $3 \mathrm{~h}$. The cells were lysed and samples were analyzed by Western blot using antibody to Egr-1 (membranes were reprobed with antibodies to $\beta$-actin to control for equal loading). The intensity of each band was quantified by densitometer. One of three similar experiments is shown.

of EGR-1 in prostate carcinoma cell lines LNCaP and PC-3, the protein expression of EGR-1 was assessed using a Western blot analyses. The cells were treated with various stimuli. FCS 10\%, and TPA strongly activates EGR-1 expression (Fig. 1A). In contrast, cisplatin and FCS $0.5 \%$ induces only a marginal activation of EGR-1. The expression of EGR-1 was strongly induced by PMA, moderately by cisplatin and marginally by FCS 10, and $0.5 \%$ (Fig. 1B). 

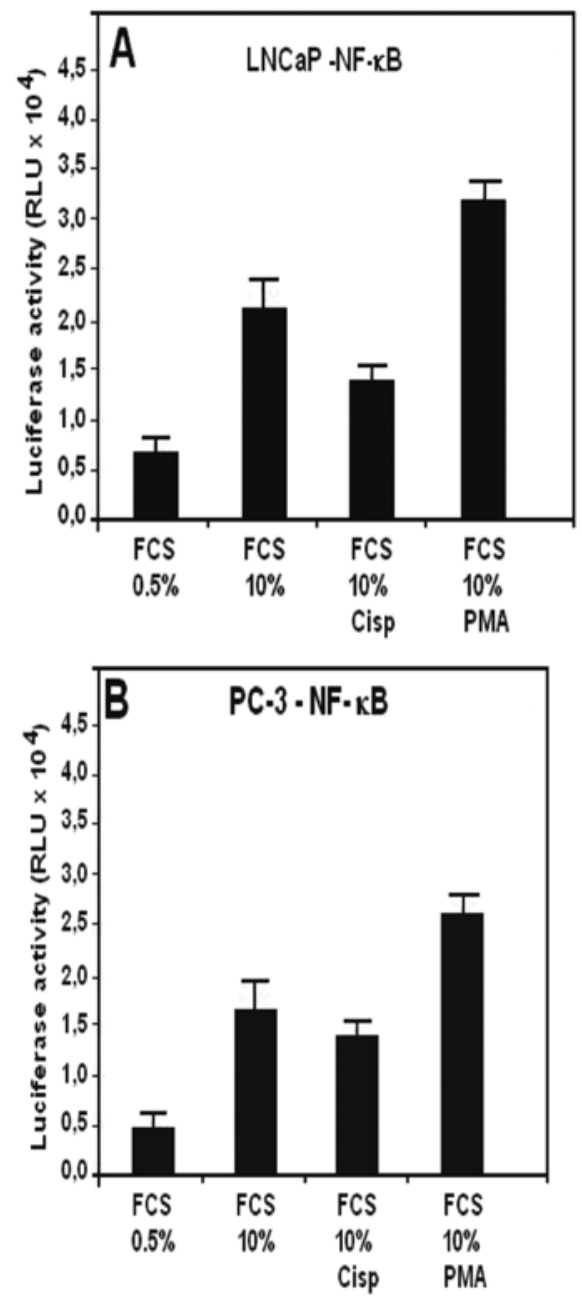

Figure 2. Involvement of Egr-1 in the activation of NF- $\mathrm{kB}$ by cisplatin and PMA in both, $\mathrm{LNCaP}$ and PC-3 prostate carcinoma cell lines. Transiently co-transfected LNCaP and PC-3 cells with 2xNF-kB-pGL-2-luciferase reporter construct and were cultured as described in Materials and methods. The cells were cultured with different concentrations of FCS (0.5\% and 10\%). After 48-h treatment the cells were cultured with FCS $10 \%$ and treated with either cisplatin $(30 \mu \mathrm{M})$ or TPA $(50 \mathrm{nM})$ and cultured for another $24 \mathrm{~h}$ before harvest. NF- $\mathrm{kB}$ activity is expressed as a fold increase of relative luciferase units as assessed by luminometer. According to the results, $\mathrm{LNCaP}$ (A) and PC-3 cells (B) transfected with the $2 \mathrm{xNF}-\mathrm{\kappa B}-\mathrm{pGL}-2$-luciferase reporter construct, treated with FCS $10 \%$, induced a 3.3- or 3.0-fold increase in NF-kB activity, respectively. Both cells treated with cisplatin $(30 \mu \mathrm{M})$ significantly decrease NF- $\kappa B$ activity to 2.1-fold (A) and 2.3-fold (B) respectively. However, LNCaP (A) and PC-3 (B) cells treated with PMA (50 nM), increase the activity of NF- $\mathrm{kB}$ to 4.9 -fold (A) and 6.5-fold in (B). One of three experiments is shown.

Effect of overexpression of Egr-1 and cisplatin/TPA in the activity of $A P-1$ and $N F-\kappa B$ in $P C-3$ and $L N C a P$ prostate carcinoma cell lines (Figs. 2 and 3). To address the effect of overexpression of Egr-1 on the activity of other genes, we examined whether overexpressed EGR-1 alone or in combination with cisplatin or TPA resulted in transcriptional activation of AP-1 and NF- $\mathrm{KB}$ in vitro luciferase assay. Thus we assayed the activity of the consensus region for AP-1 and NF- $\mathrm{KB}(34,35)$, using the pGL-2 luciferase gene reporter construct which contains a tandem repeated of $4 \times \mathrm{AP}-1$ and $2 \times \mathrm{NF}-\mathrm{\kappa B}$-binding site, by determining the luciferase activity in $\mathrm{LNCaP}$ (Fig. 2A and B) and PC-3 (Fig. 3A and B) prostate carcinoma cell lines.

In Fig. $2 \mathrm{~A}$ and $\mathrm{B}$, we show that transient overexpression of pGL-2-NF- $\mathrm{KB}$ had only a marginal effect for induction of
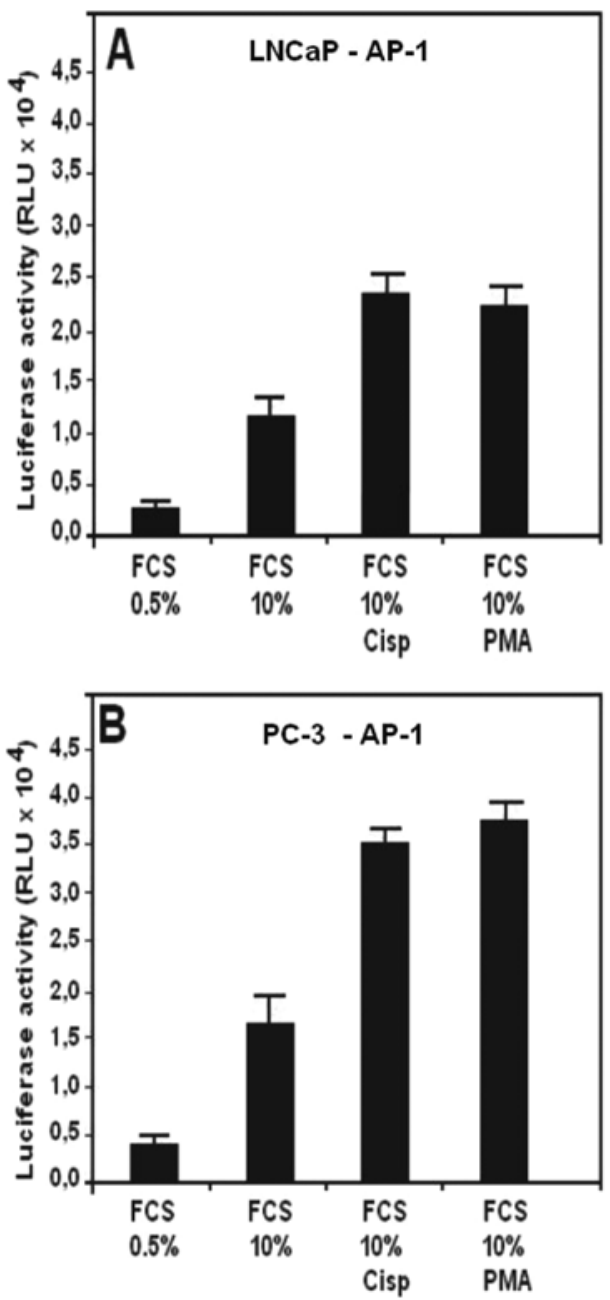

Figure 3. Involvement of Egr-1 in the activation of AP-1 by cisplatin and PMA in both, LNCaP and PC-3 prostate carcinoma cell lines. Transiently cotransfected LNCaP and PC-3 cells with 4xAP-1-pGL-2-luciferase reporter construct and pCMV-Egr-1 were cultured as described in Materials and methods. The cells were cultured with different concentrations of FCS $(0.5 \%$ and $10 \%$ ). After a 48-h treatment the cells cultured with FCS $10 \%$ were treated with either cisplatin $(30 \mu \mathrm{M})$ or TPA $(50 \mathrm{nM})$ and cultured for another $24 \mathrm{~h}$ before harvest. Luciferase activity of AP-1 is expressed as a fold increase of relative luciferase units as assessed by luminometer. According to the results, LNCaP (A) and PC-3 cells (B) transfected with the 4xAP-1-pGL-2-luciferase reporter construct, treated with FCS $10 \%$, induced a 4.8 (LNCaP)- or 4.25(PC-3) fold increase of AP-1 activity. Both cells treated with cisplatin $(30 \mu \mathrm{M})$ significantly increase the AP-1-luciferase activity to 9.2-fold (A) and 8.7-fold (B) respectively. LNCaP (A) and PC-3 (B) cells treated with PMA (50 nM) increase the activity of AP-1-luciferase to 8.9-fold (A) and 9.5-fold in (B) respectively. One of three experiments is shown.

luciferase activity in LNCaP and PC-3 cells treated with FCS $0.5 \%$. However when treated by FCS $10 \%$ and TPA, the luciferase activity increased about 4.5 -fold to 5.5 -fold over the control transfection. However, cells treated with cisplatin and resulted in less than 2.0 -fold or 2.5 -fold activation, respectively. Further, as shown in Fig. 3A and B the expression of the pGL-2-luciferase carrying the tandem repeated of AP-1, showed a reduced activity in $\mathrm{LNCaP}$ and PC-3 cells treated with FCS $0.5 \%$. An important increase of the Egr-1 activity was observed in cells treated with FCS $10 \%$. However, when treated with cisplatin the luciferase activity increase about 6.5 to 7.5 , respectively. More dramatic was the increase of luciferase activity observed in PC-3 cells transfected with the 
PC-3
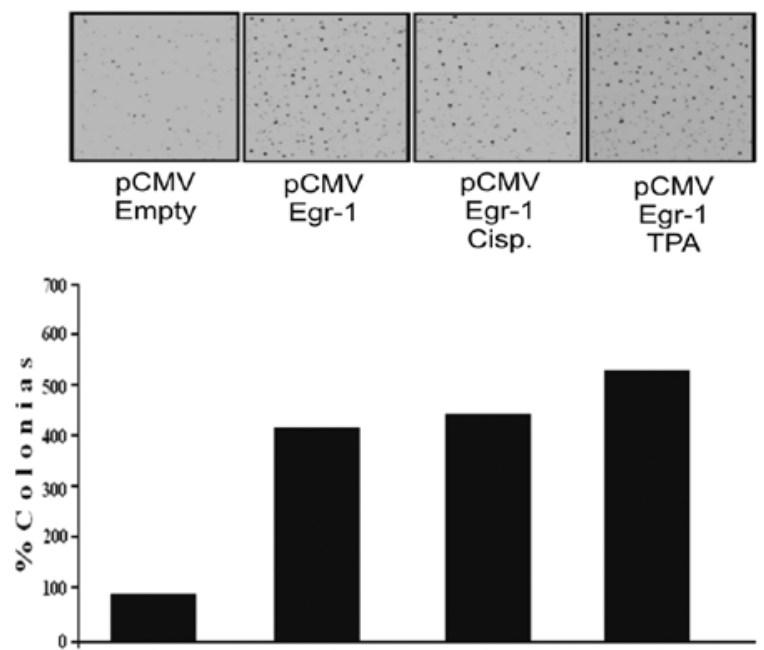

LNCaP
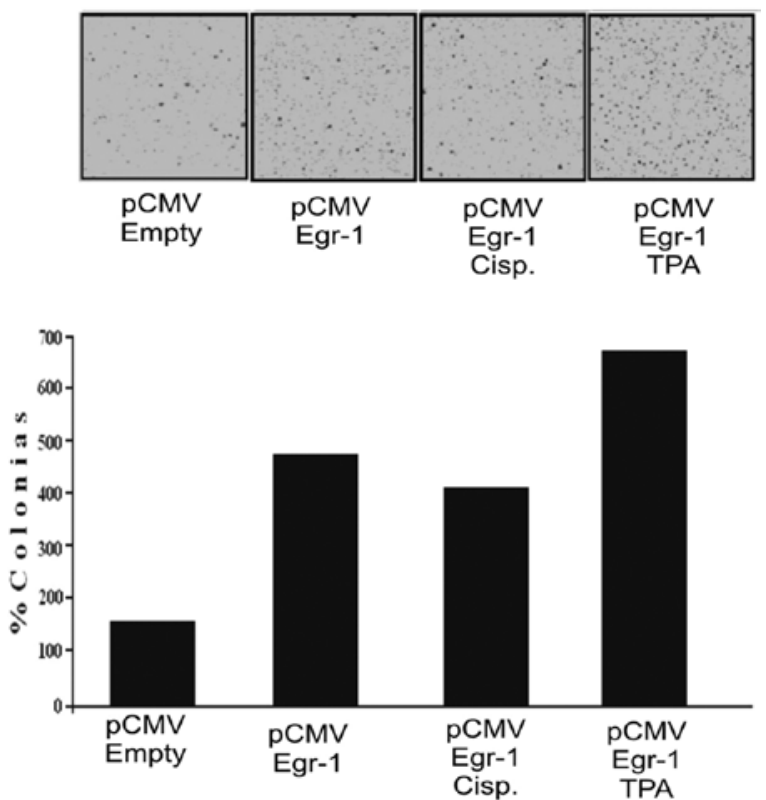

Figure 4. Overexpression of Egr-1 strongly stimulate colony formation in soft agar. PC-3 (top) and LNCaP (bottom) cells $(10,000)$ were transfected with the empty vector pCMV or pCMV-Egr-1 expression plasmid. Fourty-eight hours after cells were transfected with the above mentioned plasmids, the cells were treated with either, cisplatin $(30 \mu \mathrm{M})$ or TPA $(50 \mathrm{nM})$, cultured for $3 \mathrm{~h}$ and seeded in $0.35 \%$ agarose containing Dulbecco's modified Eagle's medium with $10 \%$ fetal bovine serum. The colony numbers were counted 2 weeks later and the cells were stained using crystal violet. In the top figures, representative wells demonstrating the total number of colonies formed by PC-3 cells transfected with the indicated plasmids, following by cisplatin or TPA induction. Bottom figures (LNCaP cells); show representative wells demonstrating the total number of colonies formed by LNCaP cells transfected with the indicated plasmids, following by cisplatin or TPA induction. One of two similar experiments is shown.

pGL-2-AP-1 reporter construct, treated with TPA, which increased the activity of luciferase about 14-fold to 15.5 -fold over the control transfection.

Overexpression of Egr-1 in PC-3 and LNCaP prostate carcinoma cells results in increased colony formation and growth in soft agar. We then tested whether overexpression of Egr-1 could influence the ability of PC-3 (top figure) and LNCaP (bottom
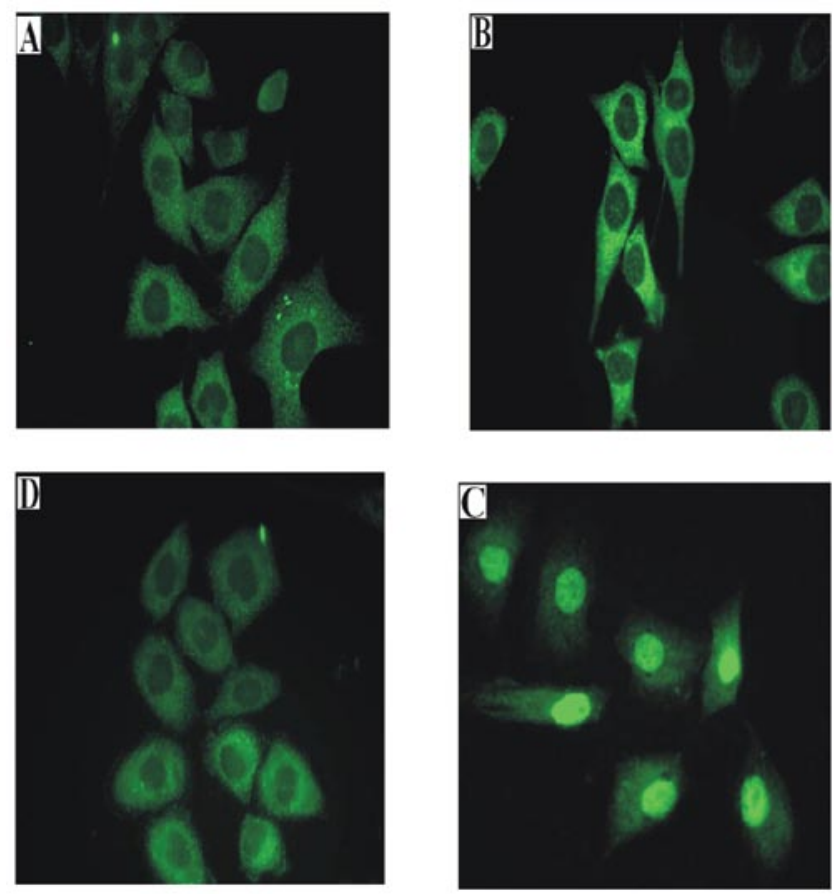

Figure 5. Egr-1 translocated to the nucleus when is overexpressed by pCMVEgr-1 vector. Fluorescence microscopy demonstrating that overexpression of Egr-1 induced nuclear co-localization of the endogenous Egr-1 and overexpressing Egr-1. Cytoplasmic activity was observed of endogenous Egr-1 (A), which increase the activity after TNF- $\alpha$ treatment (B). C and D, the translocation of Egr-1 to the nucleus as the effect of the overexpression of Egr-1 was observed. One of two similar experiments is shown.

figure) prostate carcinoma cells to form colonies in soft agar (Fig. 4). PC-3 and LNCaP cells were transfected with either; pCMV empty vector or pCMV-Egr-1 expression plasmid. At $48 \mathrm{~h}$ after transfection, the cells were treated with either, cisplatin $(30 \mu \mathrm{M})$ or TPA $(50 \mathrm{nM})$ and cultured for another $3 \mathrm{~h}$. At $3 \mathrm{~h}$ after the induction, the cells were placed into medium with soft agar, and colonies were counted after 2 weeks. Cells transfected with empty vector were unable to elicit a detectable increase in colony formation and cell growth. In contrast cells transfected with the Egr-1 expression plasmid and the same cells treated with cisplatin strongly increase the number of colonies in soft agar. Interestingly, the transfected cells treated with TPA showed the strongest effect in increasing the number of colonies in both PC-3 and LNCaP cells. These results showed that the augment in Egr-1 protein level increased the ability of prostate cancer cells to form colonies in soft agar (Fig. 4).

Overexpression of Egr-1, but not TNF- $\alpha$, induces cytoplasmic translocation of EGR-1 to the nucleus (Fig. 5). It has been shown that Egr-1 activation involves a variety of translocation depending on stimuli. To determine the effects of overexpression of Egr-1 in PC-3 cells on EGR-1 translocation, PC-3 cells were treated with TNF- $\alpha(25 \mathrm{ng} / \mathrm{ml})$ for $60 \mathrm{~min}$. Localization of EGR-1 was determined by indirect immunofluorescence microscopy with anti-Egr-1 followed by Alexa Fluor 488 (green) conjugated goat anti-rabbit secondary antibodies. The majority of the endogenous Egr-1 before after overexpression of Egr-1 is detected on the cyplasmic compart- 

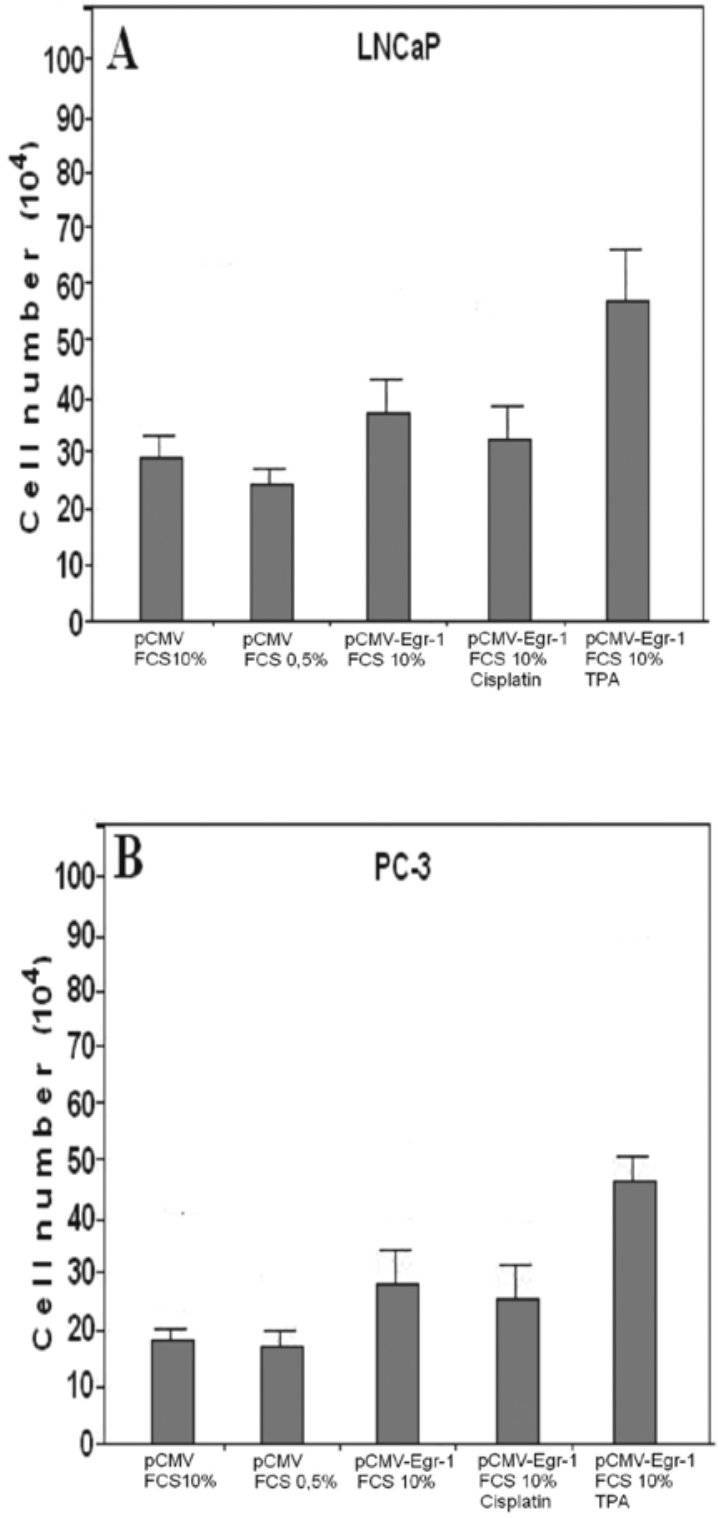

Figure 6. Evaluation of cell proliferation in $\mathrm{LNCaP}(\mathrm{A})$ and $\mathrm{PC}-3$ (B) prostate cancer cells transfected with pCMV-Egr-1 expression plasmid and treated with FCS $10 \%$, cisplatin $(30 \mu \mathrm{M})$ or TPA $(50 \mathrm{nM})$. Cell viability in transfected prostate cancer cells treated with FCS $10 \%$, cisplatin or TPA-, was evaluated with trypan blue staining. Cells were either FCS $0.5 \%$ treated (control) or treated with an increase concentration of FCS $10 \%$ or with cisplatin $(30 \mu \mathrm{M})$ or TPA $(50 \mathrm{nM})$ for $72 \mathrm{~h}$ and then analyzed. Number of cells counted or O.D. value in cells transfected with pCMV empty vector/10\% FCS (control)treatment was considered $100 \%$ and the number of cells treated with FCS $10 \%$, FCS 10\%/cisplatin and FCS 10\%/TPA-treated cells was calculated relative to this control. The data are represented as mean $\pm \mathrm{SD}$ of triplicate samples.

ment of resting PC-3 cells (Fig. 5A). TNF- $\alpha$ treatment does not induce nuclear translocation of EGR-1 but stimulates Egr-1 activity and expression in the cytoplasm (Fig. 5B). The overexpression of Egr-1, instead, induced a strong translocation and accumulation of EGR-1 in the nucleus in a timedependent manner (Fig. 5C). To further determine the effect of overexpression of Egr-1 and the the specific translocation of EGR-1, we performed co-localization analyses by staining the cells with DAPI (nuclear staining). As shown in Fig. 5D, co-localization of of EGR-1 with DAPI was detected at $60 \mathrm{~min}$ after overexpresssion of Egr-1 treatment.

Overexpression of Egr-1 in LNCaP and PC-3 prostate carcinoma cell lines preferentially increases the proliferation of prostate cancer cells treated with TPA compared to cells treated with cisplatin (Fig. 6). To determine the effect of overexpression of Egr-1 on prostate cancer cell proliferation, we investigated the Egr-1 proliferative effect on prostate cancer LNCaP and PC-3. As shown in Fig. 6, cells transfected with FCS $10 \%$ in combination with TPA $(50 \mathrm{nM})$ exhibited a similar proliferative activity in both, $\mathrm{LNCaP}$ and $\mathrm{PC}-3$ cells. The effectiveness could be observed within 2 days of treatment with an approximate $150 \%$ augment in the presence of TPA $(50 \mathrm{nM})$. Cells viability was estimated after adding and equivalent volume of a $0.125 \%$ trypan blue solution to an aliquot of the whole suspended cells and counting under the microscope the proportion of unstained versus total cells deposited in a hemacytometer. The viability in control cells was considered as $100 \%$. For cell growth and viability, cells were plated in $60 \mathrm{~mm}$ dished 1 day prior to cisplatin and TPA treatment.

As showed in Fig. 6, an increase in cell grown in pCMV-Egr-1 transfected cells in response to TPA (PMA) compared with cells transfected with pCMV empty vector. The overexpression of Egr-1 in combination with FCS $10 \%$ [36\% (LNCaP)/47\% (PC-3)] or cisplatin [21\% (LNCaP)/31\% (PC-3)] has a moderate effect on cell growth or viability compared with the strong effect on cell growth induced by the combination of Egr-1 overexpressed and TPA [103\% (LNCaP)/147\% (PC-3)]. Therefore, overexpression of Egr-1 exhibited tumor promoting activity through an increase of cell viability and the induction of cancer cells survival. Data are expressed as mean $\pm \mathrm{SD}$ of three experiments.

\section{Discussion}

To understand the molecular effects of the overexpression of EGR-1 for the tumor-promoting activity of EGR-1 in several kind of cancers, we examined its effect on the expression of transcription factors AP-1 and NF- $\kappa \mathrm{B}$, whose activity is stimulated by several other tumor promoters. We found that cisplatin, but not TPA was able to diminish the expression and activity of EGR-1 compared with $10 \%$ FCS. NF- $\mathrm{kB}$ and AP-1 play a critical role in the transcriptional regulation of genes that have been shown to suppress apoptosis and induce cellular transformation, proliferation, invasion, metastasis, chemo-resistance, radio-resistance and inflammation $(26,27,37,38)$. We also know that TPA is a potent stimulator of AP-1 trans-criptional activity and an efficient inducer of c-fos and c-jun gene expression. Induction of c-jun and c-fos transcription by cisplatin correlates with activation of AP-1, Jun kinases (JNKs) and p38, which phosphorylate transcription factors that activate these immediate early genes $(38,39)$. AP-1 is one of the transcription factors found at the receiving end of multiple signaling pathways. AP-1 is composed of either homo- or hetero-dimers of basic leucine zipper (bZIP) family members $(41,42)$. Dimerization is required for specific binding to a DNA sequence known as the TPA response element (TRE) found in the promoter region of many genes. Although the role of AP-1 in cell pro- 
liferation is well established $(41,42)$, activating mutations of this complex have never been found in human cancer. Most of the important insights into the specific function of AP-1 proteins have been established through the use of mice with either loss- or gain-of-function manipulations of various members of the bZIP protein family $(43,44)$.

No effect on ERK activity was observed. TPA, on the other hand, had a potent effect in EGR-1 expression in both, LNCaP and PC-3 cells. In contrast, cisplatin showed a negligible effect on EGR-1 expression as showed in Fig. 1. Transcriptional analysis and co-transfection experiments strongly suggest that the primary mechanism by which overexpression of EGR-1 modulate AP-1 and NF- $\kappa \mathrm{B}$ activities involves the activation of the member of the two families of the earlier proteins such as Jun and Fos $(45,46)$. The partial inhibition by cisplatin in the transcriptional activity of the $\mathrm{NF}-\kappa \mathrm{B}$, and the increasing activating of AP-1 in both LNCaP and PC-3 cells suggested different roles of AP-1 and NF- $\mathrm{BB}$ in cells overexpressing EGR-1. This activity appears to be responsible for maintaining low basal or high JNK activity in non-stimulated cells and its inhibition may lead to tumor promotion through induction of proto-oncogenes such as c-jun and c-fos, and stimulation of AP-1 activity (33).

The dynamic balance among the nuclear factors Ap-1 and $\mathrm{NF}-\kappa \mathrm{B}$, will determined the activity of several other genes, like the c-jun N-terminal kinase (JNK) and the p38 mitogenactivated protein kinase (p38MAPK) whose activities critically determines the cellular fate in response to stimuli of proliferation, differentiation and apoptosis $(47,48)$. The role of EGR-1 signaling in the processes of cell differentiation and proliferation has been clearly recognized $(49,50)$, while requirement of EGR-1 activation for apoptosis remains controversial. However, in other circumstances, they are not associated with the induction of apoptosis $(5,51,52)$.

In conclusion, we showed the critical role of the overexpression of Egr-1 signaling pathway in the regulation of NF- $\kappa$ B/AP-1-mediated activation by cisplatin and TPA. Although it has been demonstrated that Egr-1 (5,51-53) is a major nuclear factor inducing tumor cell proliferation, our data suggested that EGR-1-induced AP-1/NF- $\kappa$ B activity plays a role in tumor progression through augmentation of proliferation activity in tumor cells. We, therefore, conclude that strategies targeting the AP-1 and NF- $\kappa \mathrm{B}$ pathway may permit the development of new therapeutic methods for inhibition of Egr-1 gene activity.

\section{Acknowledgements}

We thank Dr Dan Mercola (The Sidney Kimmel Cancer Center, La Jolla, San Diego CA.) for providing us the cell lines PC-3, LNCaP and the plasmid pCMV, pCMV-Egr-1. This study was supported by the Chilean National Science Foundation FONDECYT regular grant award 1060774 and the minor intra-mural grant UTA-4712-09.

\section{References}

1. Eichelberger L, O Koch M, Eble J, Ulbright T, Juliar B and Cheng L: Maximum tumor diameter is an independent predictor of prostate-specific antigen recurrence in prostate cancer Mod Pathol 18: 886-890, 2005.
2. Virolle T, Krones-Herzig A, Baron V, Gregorio GG, Adamson ED and Mercola D: Egrl promotes growth and survival of prostate cancer cells: identification of novel Egrl target genes. Int J Biol Chem 278: 11802-11810, 2003.

3. Eid MA, Kumar MV, Iczkowski KA, Bostwick DG and Tindall DJ: Expression of early growth response genes in human prostate cancer. Int Cancer Res 58: 2461-2472, 1998.

4. Scharnhorst V, Menke AL and Attema J: EGR-1 enhances tumor growth and modulates the effect of the Wilms' tumor 1 gene products on tumorigenicity. Oncogene 19: 791-800, 2000.

5. Pignatelli M, Luna-Medina R, Perez-Rendon A, Santos A and Perez-Castillo A: The transcription factor early growth response factor-1 (EGR-1) promotes apoptosis of neuroblastoma cells. Int Biochem J 373: 739-746, 2003.

6. Houston P, Campbell CJ, Svaren J, Milbrandt J and Braddock M: The transcriptional corepressor NAB2 blocks Egr-1-mediated growth factor activation and agiogenesis. Int Biochem Communications 283: 480-486, 2001.

7. Collins S, Lutz MA, Zank PA, Anders R, Kersh G and Powell JD: Opposing regulation of T cell function by Egr-1/NAB2 and Egr-2 and Egr-3. Int Eur J Immunol 38: 528-536, 2008.

8. Amorino G, Hamilton V, Valerie K, Dent P, Lammering G and Schmidt-Ullrich R: Epidermal growth factor receptor dependence of radiation-induced transcription factor activation in human breast carcinoma cells. Int Mol Biol Cell 13: 2233-2244, 2002.

9. Adamson ED and Mercola D: Egr1 transcription factor, multiple roles in prostate tumor cell growth and survival. Tumour Biol 23: 93-102, 2002.

10. Banks MF, Gerasimovskaya EV, Tucker D, Frid MG, Carpenter TC and Stenmark KR: Egr-1 antisense oligonucleotide inhibit hypoxiainduced proliferation of pulmonary artery adventitial fibroblast. Int J Appl Physiol 98: 732-738, 2004.

11. White E: Life death, and the pursuit of apoptosis. Genes Dev 10: $1-15,1996$.

12. Nair P, Muthukkumar S, Sells SF, Han SS, Sukhatme VP and Rangnekar VM: Early growth response-1-dependent apoptosis is mediated by p53. J Biol Chem 272: 20131-20138, 1997.

13. Liu C, Rangnekar VM, Adamson E and Mercola D: Suppression of growth and transformation and induction of apoptosis by EGR-1. Cancer Gene Ther 5: 3-28, 1998.

14. Fahmy R, Dass C, Sun L, Chesterman C and Khachigian L: Transcription factor Egr-1 supports FGF-dependent angiogenesis during neovascularization and tumor growth. Nat Med 9: 1026-1032, 2003.

15. Svaren J, Ehrig T, Abdulkadir S, Ehrengruber M, Watson M and Milbrandt J: EGR1 target genes in prostate carcinoma cells identified by microarray analysis. J Biol Chem 275: 38524-38531, 2000.

16. Han S, Keum Y-S, Seo H-J and Surh Y-J: Curcumin suppresses activation of NF- $\mathrm{KB}$ and AP-1 induced by phorbol ester in cultured human promyelocytic leukemia cells. Biochem Mol Biol 35: 337-342, 2002.

17. Dhar A, Young MR and Colburn NH: The role of AP-1, NF-kappaB and ROS/NOS in skin carcinogenesis: the JB6 model is predictive. Mol Cell Biochem 234-235: 185-193, 2002.

18. Suzukawa K, Weber TJ and Colburn NH: AP-1, NF-kappa-B, and ERK activation thresholds for promotion of neoplastic transformation in the mouse epidermal JB6 model. Environ Health Perspect 110: 865-870, 2002.

19. Quantin B and Breathnach R: Epidermal growth factor stimulates transcription of the c-Jun protoncogene in rat fibroblasts. Nature 334: 538-539, 1988.

20. Goldgaber D, Harris H, Hla T, Maciag T, Donnelly R, Jacobsen J and Gajdusek D: Interleukin 1 regulates synthesis of amyloid beta-protein precursor mRNA in human endothelial cells. Proc Natl Acad Sci USA 86: 7606-7610, 1989.

21. Karin M: The regulation of AP-1 activity by mitogen-activated protein kinases. J Biol Chem 270: 16483-16486, 1995.

22. Baeuerle PA and Henkel T: Function and activation of NF- $\kappa$ B in the immune system. Annu Rev Immunol 12: 141-179, 1994.

23. Blackwell TS and Christman JW: The role of nuclear factorkappa B in cytokine gene regulation. Cell Mol Biol 17: 3-9, 1997.

24. Adcock IM: Transcription factors as activators of gene transcription: AP-1 and NF-kappa B. Monaldi Arch Chest Dis 52: 178-186, 1997.

25. Mueller J and Pahl H: Assaying NF- $\kappa \mathrm{B}$ and AP-1 DNA-binding and transcriptional activity. Methods Mol Biol 99: 205-216, 2000.

26. Rupec RA and Baeuerle PA: The genomic response of tumor cells to hypoxia and reoxygenation: differential activation of transcription factors AP-1 and NF-kB. Eur J Biochem 234: 632-640, 1995. 
30. Parra E and Ferreira J: The effect of siRNA- Egr-1 and camptothecin on growth and chemosensitivity of breast cancer cell lines. Oncol Rep 22: 1159-1165, 2010.

31. Parra E and Ferreira J: Knockdown of the c-Jun-N-terminal kinase expression by siRNA inhibits MCF-7 breast carcinoma cell lines growth. Oncol Rep 24: 1339-1345, 2010.

32. Parra E, Ortega A and Saenz L: Downregulation of Egr-1 by siRNA inhibits growth of human prostate carcinoma cell line PC-3. Oncol Rep 22: 1513-1518, 2009.

33. Inostroza J, Saenz L, Calaf G, Cabello G and Parra E: Role of the phosphatase PP4 in the activation of JNK-1 in prostate carcinoma cell lines PC-3 and LNCaP resulting in increased AP-1 and EGR-1 activity. Biol Res 38: 163-178, 2005.

34. Parra E, McGuire K, Hedlund G and Dohlsten M: Overexpression of p65 and c-Jun substitutes for B7-1 costimulation by targeting the CD28RE within the IL-2 promoter. J Immunol 160: 5374-5381, 1998.

35. Parra E, Varga M, Hedlund G, Kalland T and Dohlsten $M$ : Costimulation by B7-1 and LFA-3 targets distinct nuclear factors that bind to the interleukin-2 promoter: $\mathrm{B} 7-1$ negatively regulates LFA-3-induced NF-AT binding. Mol Cell Biol 17: 1314, 1997.

36. Aguilera C, Hoya-Arias R, Haegeman G, Espinosa L and Bigas A: Recruitment of Ikappa B alpha to the hest 1 promoter is associated with transcriptional repression. Proc Natl Acad Sci USA 101: $16537-16542,2004$.

37. Zhou H, Lin A, Gu Z, Chen S, Park N and Chiu R: 12-O-tetradecanoylphorbol-13-acetate (TPA)-induced c-Jun N-terminal kinase (JNK) phosphatase renders immortalized or transformed epithelial cells refractory to TPA-inducible JNK activity. J Biol Chem 275: 22868-22875, 2000.

38. Mohanty S, Huang $\mathbf{J}$ and Basu A: Enhancement of cisplatin sensitivity of cisplatin-resistant human cervical carcinoma cells by bryostatin 1. Clin Cancer Res 11: 6730-6737, 2005.

39. Lipshtat A, Purushothaman S, Iyengar R and Maayan A: Functions of bifans in context of multiple regulatory motifs in signaling networks. Biophys J 94: 2566-2579, 2008

40. Sánchez I, Aznar S, Martínez M, Lacal J and Perona R: Cell stress and MEKK1-mediated c-Jun activation modulate NF- $\kappa$ B activity and cell viability. Mol Biol Cell 13: 2933-2945, 2002.

41. Angel P and Karin M: The role of Jun, Fos, and the AP-1 complex in cell proliferation and transformation. Biochem Biophys Acta 1072: 129-157, 1991.

42. Deng T and Karin M: JunB differs from c-Jun in its DNA-binding and dimerization domains, and represses c-Jun by formation of inactive heterodimers. Genes Dev 7: 479-490, 1993.
43. Wagner EF: AP-1-introductory remarks. Oncogene 20: 2334-2335, 2001.

44. Kawaida R, Ohtsuka T, Okutsu J, Takahashi T, Kadono Y, Oda H, Hikita A, Nakamura K, Tanaka S and Furukawa H: Jun dimerization protein 2 (JDP2), a member of the AP-1 family of transcription factor, mediates osteoclast differentiation induced by RANKL. J Exp Med 197: 1029-1035, 2003.

45. Heinrich R, Livne E, Ben-Izhak O and Aronheim A: The c-Jun dimerization protein 2 inhibits cell transformation and acts as a tumor suppressor gene. J Biol Chem 279: 5708-5715, 2004.

46. Esteve L, Haby C, Rodeau J, Humblot N, Aunis D and Zwiller J: Induction of c-fos, jun B and egr-1 expression by haloperidol in PC12 cells: involvement of calcium. Neuropharmacology 34: 439-448, 1995 .

47. Morawietz H, Ma YH, Vives F, Wilson E, Sukhatme V, Holtz J and Ives H: Rapid induction and translocation of Egr-1 in response to mechanical strain in vascular smooth muscle cells. Circulation Res 84: 678-687, 1999.

48. Karin M and Delhase M: JNK or IKK, AP-1 or NF-kappaB, which are the targets for MEK kinase 1 action? Proc Natl Acad Sci USA 95: 9067-9079, 1998.

49. Chowdhury T, Salter DM, Bader DL and Lee DA: Signal transduction pathways involving p38 MAPK, JNK, NFKB and AP-1 influences the response of chondrocytes cultured in agarose constructs to IL-1 $\beta$ and dynamic compression. Inflamm Res 57: 306-313, 2008.

50. Min IM, Pietramaggiori G, Kim F, Passegué F, Stevenson K and Wagers A: The transcription factor EGR1 controls both the proliferation and localization of hematopoietic. Cell Stem Cell 4: 380-391, 2008

51. Gottschalk A, Joseph L and Quintáns J: Differential induction of Egr-1 expression in WEHI-231 sublines does not correlate with apoptosis. Eur J Immunol 23: 2011-2015, 1993.

52. Boone D, Qi Y, Li Z and Hann S: Egrl mediates p53-independent c-Myc-induced apoptosis via a noncanonical ARF-dependent transcriptional mechanism. Proc Natl Acad Sci USA 108: 2 632-637, 2011.

53. Zhang LS, Ma HW, Greyner HJ, Zuo W and Mummert M: 1,2,3 inhibition of cell proliferation by CD44: Akt is inactivated and EGR-1 is down-regulated. Cell Prolif 43: 385-395, 2010. 